\title{
The Impact of COVID-19 on Gender Inequality: A Study on Cross-Sector Inequality in the US
}

\author{
Siyue Han \\ Washington University in St. Louis \\ han.siyue@outlook.com
}

\begin{abstract}
The COVID-19 pandemic has resulted in substantial employment losses in the US. To understand how this impact fell on male and female workers unevenly, I empirically investigate the impacts of COVID-19 on the gender inequality in labor markets and analyze the variation in effects across sectors. I find that the COVID-19 pandemic influences all sectors to different degrees, with the tertiary (service) sector hit the hardest. The pandemic has also exacerbated gender inequality in certain sectors, but not all: women working in the tertiary sector are most economically harmed, while sectors that rely mostly on knowledge and technology tend to work remotely and generally have the least impact in working hours from the pandemic. The intersectionality of race, gender, and educational attainment also contributes to the disparities in labor markets across all sectors. Results also show that marriage benefits employment, and that having children under the age of five could slightly disadvantage workers in the labor markets.
\end{abstract}

\section{CCS CONCEPTS}

- Social and professional topics $\rightarrow$ User characteristics; Gender.

\section{KEYWORDS}

Gender inequality, labor markets, COVID-19, cross-sector

\section{ACM Reference Format:}

Siyue Han. 2021. The Impact of COVID-19 on Gender Inequality: A Study on Cross-Sector Inequality in the US. In The 2021 12th International Conference on E-business, Management and Economics (ICEME 2021), fuly 17-19, 2021, Beijing, China. ACM, New York, NY, USA, 9 pages. https://doi.org/10.1145/ 3481127.3481148

\section{INTRODUCTION}

The US has witnessed and experienced one of the worst pandemics in scale and scope of destruction-the COVID-19, accompanied by its vast and unprecedented economic consequences in both goods markets and labor markets. COVID-19 has caused a 20 percent decline of the US economy's GDP, 23 percent loss of jobs, and a 16 percent decrease in total wage income of the US [1]. With great uncertainty about the enduring pandemic and lack of confidence in long-term economic prospects, households initially increased

Permission to make digital or hard copies of all or part of this work for personal or classroom use is granted without fee provided that copies are not made or distributed for profit or commercial advantage and that copies bear this notice and the full citation on the first page. Copyrights for components of this work owned by others than ACM must be honored. Abstracting with credit is permitted. To copy otherwise, or republish, to post on servers or to redistribute to lists, requires prior specific permission and/or a fee. Request permissions from permissions@acm.org.

ICEME 2021, fuly 17-19, 2021, Beijing, China

(C) 2021 Association for Computing Machinery.

ACM ISBN 978-1-4503-9006-4/21/07 . \$ \$15.00

https://doi.org/10.1145/3481127.3481148 their consumption sharply in retail, credit card spending, and food but later decreased their consumption of goods and services in general [2]. Social distancing measures have also contributed to the reduced spending in the "in-person" sectors such as retail and restaurants. Based on their SIR-Macro model, Eichenbaum et al. [3] estimated that average aggregate consumption would decrease by 4.7 to 17 percent if containment measures are implemented with the side effect of demotivating spending. Not only in aggregate consumption, the reduced level of income also brings along a fall in aggregate investment. In particular, people's uncertainty about this pandemic is also evident in its impact on the volatility of financial markets, shown to be highly sensitive to the new infection cases and the fatality ratio at both global and US national levels [4; 5]. Baek et al. [4] document differences in volatility across stock market sectors, with significantly more systematic risks for defensive industries like telecommunication but less systematic risks for aggressive industries like automobiles.

All the shocks above contribute to an overall decrease in factors of production. Among all, labor is severely impacted: COVID-19 has so far led to a one percent spike in unemployment and a 0.7 percent decrease in the labor force participation and working hours in the US. However, the demand and supply shocks have differed degrees of impact across sectors. Tele-commutable sectors are more resilient to the pandemic, so are sectors more susceptible to infection, due to higher proportion of essential workers in these occupations. Among those more affected sectors, industries involving transportation are more constrained by demand-side shocks, while sectors concerning manufacturing and services are more constrained by supply-side shocks. Industries like tourism and restaurants face coexisting supply and demand shocks $[6 ; 1]$. This ongoing global pandemic has varied impacts on labor markets across countries. Countries most negatively impacted by the current pandemic are the ones that suffered most from the previous financial crisis, such as Spain and Italy, whose preexisting vulnerabilities such as high unemployment and severe inequality will likely be exacerbated [7;8]. In a strongly interrelated world, the amplified differences among countries could leave intensified economic turbulence by affecting global trade and supply chains. Vidya and Prabheesh [9] document a significant decline in trade interconnectedness and density among countries as well as a structural change in global trade networks.

The severity of COVID-19's economic impacts is manifested in the aforementioned multiple aspects. Under these grave repercussions, other research indicates that workers experienced differently in the midst of the pandemic-depending on their gender. The issue of gender inequality has prevailed in the labor markets for a long time and is persistently discussed as the structure and division of labor markets evolve in the past decades. Since the outbreak of COVID-19, emerging literatures acknowledge that this pandemic 
exacerbated the gender gap in labor markets worldwide. Growing evidence $[10 ; 11 ; 7 ; 12]$ suggests COVID-19 has a significantly more adverse impact on women's employment, reflected by job losses, reduction in working hours, and transition to part-time or remote working. The gender pay gap, as England [13] argues, has two major sources: segregation of jobs and mothers' responsibilities for childrearing. These two factors, to a large extent, are irrelevant but reinforcing each other. In particular, the author contends that segregation is maintained by employers' discriminatory hiring from the demand side and female workers' compliance with social norms from the supply side. In line with England [13]'s arguments, the worsened gender inequality incurred by COVID-19 could be mainly attributed to the following two reasons:

Female-dominated industries (e.g., service, education, tourism) are hit the hardest by COVID-19. Alon et al. [14] assert that the social distancing measures have a more considerable impact on sectors with higher female employment. By assessing the sectors that allow for remote working and critical sectors (e.g., healthcare), the authors suggest that women are more vulnerable to employment losses during a pandemic recession. Farré et al. [15]'s findings also confirm that women were affected slightly more by unemployment due partly to their heavier representation in sectors that were shut down (e.g., hospitality, service) or unable to work remotely (e.g., retail) during COVID-19. Another potential reason could be that sectors with higher female employment rates involve more interpersonal elements (e.g., communication, teamwork, and customer handling) and less reliance on higher digital skills [16]. Cao et al. [17] focus on the education sector and provide implications for women's employment in general. Using data from a US online education gig platform, the authors argue that the labor supply of female workers increases by a smaller amount than that of their male counterparts, thus illustrating a growing gender employment gap.

The COVID-19 pandemic triggers a surged demand for childcare and domestic labor. Collins et al.[18]'s research denotes disproportionately reduced work hours for mothers with young children. With the closures of schools and daycare centers, mothers are more likely to scale back work than fathers to satisfy the increased domestic labor and childcare demands [10]. Other caregivers such as grandparents cannot share part of the childcare responsibilities because of social distancing rules [19]. In the aftermath of the pandemic, Qian et al. [20] demonstrate that the gender employment gap widened most for parents of elementary school-aged children, with a more pronounced impact on less-educated parents. However, their research stays on the individual level. Reichelt et al. [21] analyze household work arrangments at the couple-level, using samples from the US, Germany, and Singapore, and examine the impacts of changed labor division at home/work on gender-role attitudes in the context of COVID-19. They argue that men who transition to unemployment but whose partners remain employed exhibit more egalitarian gender-role attitudes due to more unconventional household labor arrangements, while women who become unemployed adopt more traditional gender-role attitudes.

Recent literature has not reached a consensus over the long-term effects of COVID-19 on gender inequality. Richardson and Denniss [22] are not optimistic about the long-term prospects of the pandemic, as they discover that the current COVID-19 response policies have disproportionately benefited men instead of remedying the widening gender gap. The stimulus spending policies predominantly targeted male-dominated industries such as construction and infrastructure, rather than retail, hospitality, and service sectors, where female workers suffered employment losses the most. Alon et al. [23] also expect gender inequality to continue exacerbating throughout the recovery from this pandemic recession, because women are more likely to drop out of the labor force or return to part-time jobs only if they become unemployed during the pandemic. In contrast, men have more chances to find full employment in the future. However, they are positive with COVID-19's long-run impacts in greater work flexibility and improved gender norms due to more childcare responsibility shifted to fathers.

This paper confirms the recent findings that the COVID-19 pandemic exacerbates gender inequality in labor markets and discovers varied impacts on female workers across sectors due to the pandemic. It is reasonable that gender inequality across sectors is impacted distinctively due to different levels of vulnerability to the pandemic, demand for in-person work, and gender distribution. However, to which extent gender inequality is affected within each sector will be the problem to address for this paper. As two crucial labor characteristics, employment status and working hours will be the main foci of this paper to reflect gender inequality in labor markets. Given the working from home trend that arises after the pandemic, this paper also investigates the shift to working remotely as another dimension of interest.

\section{EMPIRICAL STRATEGY}

\subsection{Data}

This paper used the Current Population Survey (CPS) from Integrated Public Use Micro Samples (IPUMS) as the major source of data. The CPS is a nationwide monthly consumer survey conducted on 60,000 US households by the U.S. Census Bureau and the Bureau of Labor Statistics (BLS), and IPUMS is a project supported by the University of Minnesota that provides integrated survey data across the globe, including the CPS. The CPS offers a variety of variables such as demographic characteristics including age, gender, educational attainment, race, and marital status, labor characteristics including labor force participation, employment status, working hours, industry, and occupation, as well as household characteristics (e.g., the number of children and the number of siblings within each household). Recently, CPS also conducted surveys specifically regarding the COVID-19 outcome, such as the switching to remote work due to the pandemic.

The sample consists of adult civilians in the labor force during two time periods: the second quarter (from April to June) in 2019 and the second quarter in 2020. Among the 317,725 observations in total, $47.81 \%$ are women, and $7.19 \%$ are unemployed (Table 1 ). In regard to the discussion of working hours and working remotely due to COVID-19, the sample is restricted to only employed individuals and therefore has a smaller sample size for these two dependent variables. The average working hours at all jobs per week is around 39.6 hours out of 274,731 respondents, among whom female workers worked for approximately 37.5 hours per week on average, about 4 hours less than their male counterparts (Table 2). Moreover, based 
Table 1: Employment Status

\begin{tabular}{lll}
\hline Employment Status & Frequency & Percent \\
\hline At work & 280,871 & 88.40 \\
Has job, not at work last week & 13,996 & 4.41 \\
Unemployed, experienced worker & 21,780 & 6.85 \\
Unemployed, new worker & 1,078 & 0.34 \\
Total & 317,725 & 100.00 \\
\hline
\end{tabular}

Table 2: Working Hours at All Jobs per Week by Gender

\begin{tabular}{llllll}
\hline Gender & Observations & Mean & Std. Dev, & Min & Max \\
\hline Female & 131,024 & 37.484 & 11.012 & 0 & 141 \\
Male & 143,707 & 41.591 & 11.288 & 0 & 149 \\
Total & 274,731 & 39.632 & 11.344 & 0 & 149 \\
\hline
\end{tabular}

on the survey responses, $9.12 \%$ of the respondents switched to working remotely because of COVID- 19 .

\subsection{Sector Classification}

The IPUMS CPS provides a 13-industry classification: agriculture, forestry, and fisheries; mining; construction; manufacturing; transportation, communications, and other public utilities; wholesale trade; retail trade; finance, insurance, and real estate; business and repair services; personal services; entertainment and recreation services; professional services; and public administration. Despite this comprehensive classification, I further classify these 13 industries into fewer sectors to discover general patterns across sectors. The three-sector model developed in the last century does not apply well to sector classification in the 21 st century, mostly because of the current rapid expansion of the tertiary (services) sector. To stay in tune with the evolution of sectors and identify nuanced variations within the tertiary sector, the classification of sectors in this paper is extended to five sectors, adding quaternary and quinary sectors to the original three-sector model. The respondents' working industries are classified into the primary, secondary, tertiary, quaternary, and quinary sectors. The primary sector mainly consists of agriculture and extraction; the secondary sector contains construction, manufacturing, and utilities; the largest sector which occupies $61.7 \%$ of the labor market-the tertiary sector-includes all service-related industries (communication, entertainment, transportation, financial services, and so on); the quaternary sector, the knowledge and research sector, contains all the education-related industries and has the highest percentage of female workers; and lastly, the quinary sector is composed of public administration, membership organizations, and religious groups.

As predicted, sectors present different employment characteristics in general. The tertiary sector has the highest average unemployment rate $(7.60 \%)$, whereas the quinary sector has the lowest average unemployment rate $(2.97 \%)$. In terms of working hours, the primary sector has the highest average working hours, while the lowest average working hours is 38.6 hours for the quaternary sector. In Figure 1, the female ratio across all five sectors does not demonstrate significant change throughout 2019-2020, and the average working hours also stays relatively stable over the two years (Figure 1). Nonetheless, the unemployment rates for all sectors surged when COVID-19 broke out (Figure 1).

\subsection{Models}

I address the economic impacts of the COVID-19 pandemic from three dimensions of interest: employment status, working hours, and shift in working mode. Ideally, I would have included hourly wages to measure the respondents' economic gain. However, I did not have a proper data source for hourly wages that span from pre-COVID to post-COVID time, and many jobs in more advanced sectors are not paid hourly, but monthly.

Similar to previous research [21; 15], models used in this paper also include the female indicator and the COVID-19 indicator to assess the gender inequality in the impact of the pandemic. However, the COVID-19 indicator I use serves to separate two time periods: from April to June in 2019 and in 2020. I choose the second quarter for comparison because it was when the economy started to experience repercussions by the lockdown, and when the Black Lives Matter movement did not yet happen-which might otherwise distract us from the focus of this paper, the pandemic. I also add the number of children under the age of five as an independent variable to further examine whether the amount of childcare affects women's economic performance in the labor markets. Furthermore, my models are designed to identify sectoral differences. While many present studies consider whether the industries are essential or critical and teleworkable as part of categorizing methods $[16 ; 8 ; 14]$, I instead use a five-sector classification based on the levels of economic activity, because classifying industries by the standards of "essential" and "teleworkable" will only produce fairly predictable results.

The first section of analysis pertains to the impact of COVID-19 on gender inequality across sectors in terms of employment status, using the following reduced-form logistic regression model for the 

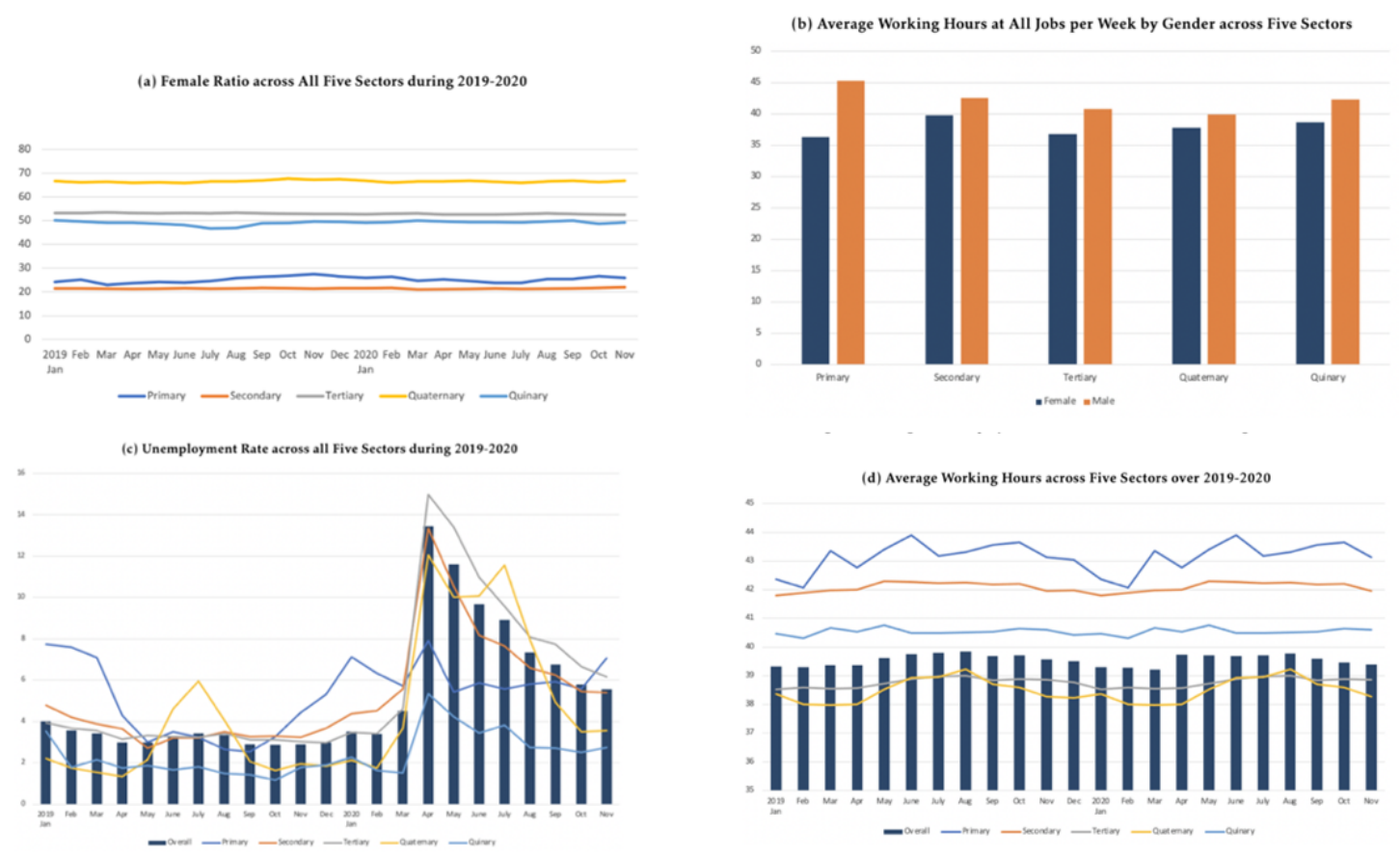

Figure 1: The gender breakdown of average working hours, and the change of female ratio, unemployment rate, and average working hours across five sectors over 2019-2020

five different sectors:

$$
\begin{gathered}
\operatorname{Pr}\left(E_{E m p_{i}}=1\right)=h\left(\beta_{0}+\beta_{1} G n d r_{i}+\beta_{2} \operatorname{COVID}_{i}+\beta_{3} G_{n d r}\right. \\
\left.\times \operatorname{COVID}_{i}+\beta_{4} N o C \leq 5_{i}+\beta_{5} x_{i}\right)
\end{gathered}
$$

where $h(\cdot)=\frac{\exp (\cdot)}{1+\exp (\cdot)}$ and the dependent variable is a binary indicator of the respondents' employment status (unemployed $=0$, employed $=1$ ), and independent variables include a dummy variable of gender (Male=0, Female $=1$ ), pre-/post-COVID indicator (April to June in $2019=0$, April to June in $2020=1$ ), and interaction between gender and the COVID-19 pandemic. The interactive term is designed to capture the changes in employment status based on gender. $\mathrm{X}_{\mathrm{i}}$ includes all the demographic variables: age, white or non-white, marital status, and educational attainment.

On the condition of employment, I ran a linear regression model of the impact of COVID-19 on working hours across five sectors as shown below:

$W k h r_{i}=\beta_{0}+\beta_{1} G_{n d r}+\beta_{2} C_{C O V I D}+\beta_{3} G n d r_{i} \times C_{C O V I D}+\beta_{4} \mathrm{NoC}$ $\leq 5_{i}+\beta_{5} x_{i}+\varepsilon_{i}$

where the dependent variable is the working hours per week at all jobs, and the independent variables are the same to those in the previous model.

Additionally, I estimate the influence of the pandemic on women switching to remote work of the employed respondents with the following logistic regression model:

$\operatorname{Pr}\left(\right.$ Rmt $\left._{i}=1\right)=h\left(\beta_{0}+\beta_{1}\right.$ Gndr $_{i}+\beta_{2}$ Sector $_{i}+\beta_{3}$ Gndr $_{i} \times$ Sector $_{i}$ $\left.+\beta_{4} N o C \leq 5_{i}+\beta_{5} x_{i}\right)$ where $h(\cdot)=\frac{\exp (\cdot)}{1+\exp (\cdot)}$ and the dependent variable is whether the workers switch to remote working for pay due to the COVID-19 pandemic. Note that this model does not use a pre-/post-pandemic indicator, because the survey response to the question of whether the workers switched to working remotely due to COVID-19 is collected after the pandemic breaks out, and the survey question itself "At any time in the last 4 weeks, did (you/name) telework or work at home for pay because of the coronavirus pandemic?" already reflects a change in working mode caused by COVID-19, thereby making a COVID-19 indicator unnecessary. Moreover, this model does not capture variations within each sector, because the ability to switch to remote work is a trait for the entire sector.

\section{RESULTS}

\subsection{Employment Status}

As expected from previous research on the economic impacts of COVID-19 [11], the increase in the unemployment rate is very pronounced. $5.63 \%$ of the respondents were unemployed in the second quarter of 2019 , and the unemployment rate rose to $11.01 \%$ in the second quarter of 2020. These numbers correspond with the numbers provided by the US Bureau of Labor Statistics.

Table 3 documents significant employment losses after the COVID-19 pandemic across all sectors. Among all, the secondary sector (manufacturing), tertiary sector (service), and quaternary sector (education and knowledge-related) are heavily impacted. The two most disrupted industries are Personal Services (which include hospitality and clothing industries) as well as Entertainment and 
Table 3: Results for Employment Status

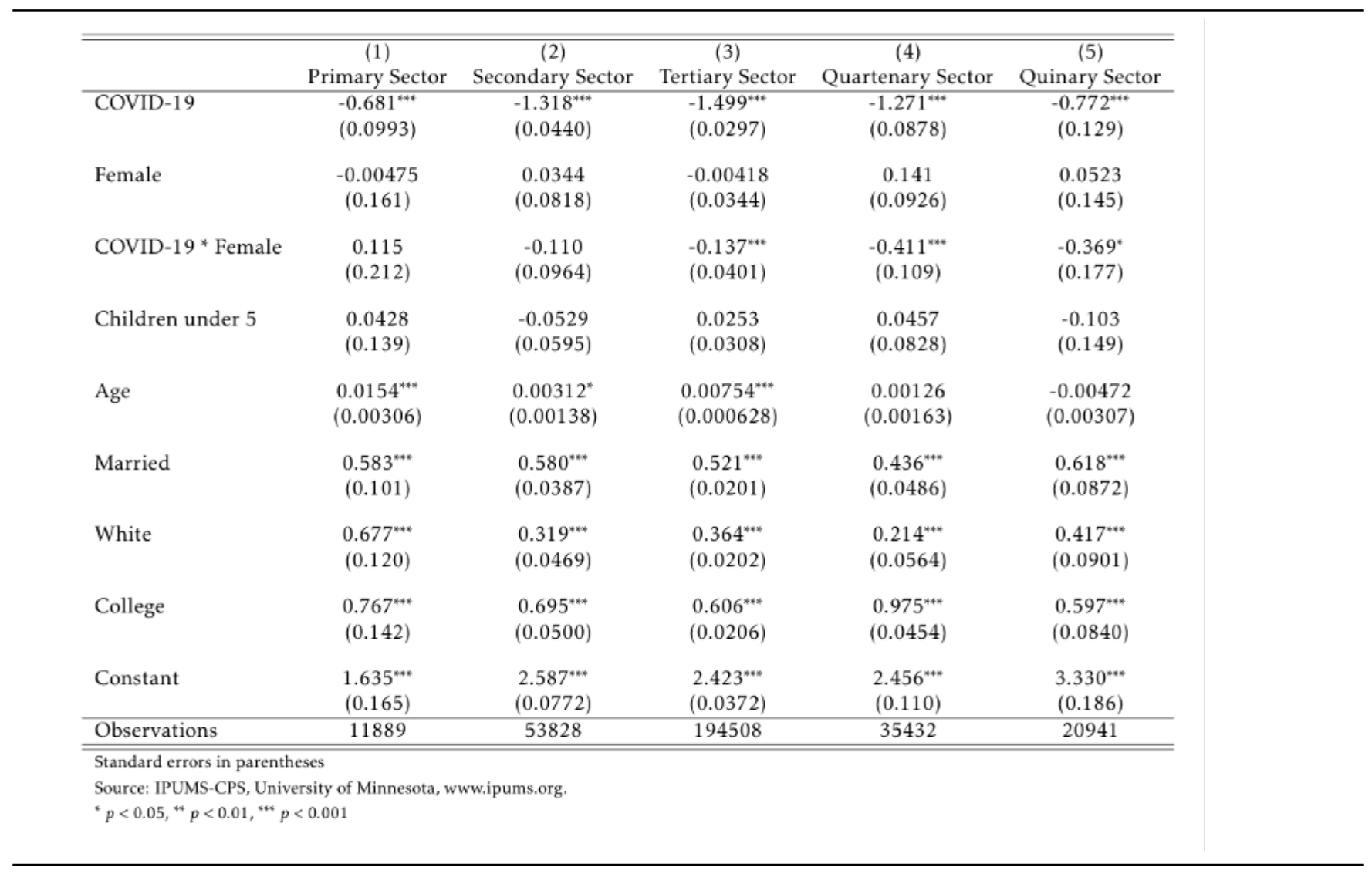

Recreation Services, which demonstrates the shock from the travel restriction and lockdown policies (Table 4). Huang et al. claim that the damage on the hospitality and leisure industries is associated with the business closure policies [24].

Although the coefficients for Female are not significantly different from zero, the interactive term reveals a severe "she-cession" in labor markets, that women experience more employment losses than men [25]. Female workers in the tertiary and quaternary sectors bear the most severe impacts by the pandemic compared to their male counterparts. Both of these sectors have the most female employment percentage [14]. In particular, women working in the tertiary sector experienced a 13-point decrease in employment after the pandemic, and women in the quaternary sector experienced an over 40-point drop. As predicted by recent studies [11], this result illustrates that women's employment status has been more harshly impacted than men's in sectors where women are most represented.

In addition to gender, other individual characteristics also affect the workers' employment outcomes. Although having children under five in the household does not yield a significant result, marital status plays an important role in affecting the workers' employment status. Respondents who are married are more likely to secure their jobs after COVID-19 across all sectors, confirming Béland et al.[6]'s findings that the pandemic has overally less negative impact on the labor participation of married people. The reason why unmarried people are more likely to be unemployed is primarily because of their lower education level and deficient working experiences, as well as the discrimination against unmarried people in the labor markets. Moreover, white, educated workers are less affected by COVID-19 in all sectors. The low-wage, primary sector has the most severe racial disparities among all, with the white workers having a $70 \%$ chance to remain employed.

\subsection{Working Hours}

As shown in Table 5, COVID-19 lowers the working hours for the secondary, tertiary, and quinary sectors. Notably, construction, manufacturing, and wholesale trade industries are most severely affected in terms of working hours (Table 6).

Considerable disparities exist based on gender across all sectors. The primary sector has the widest gender gap in working hours. Hours worked per week drops significantly for married women in the tertiary sector because of COVID-19. This is due mostly to women's shifting to domestic labor and childrearing after the pandemic. Women in the quinary sector (public administration and cultural/religious groups) experience the slightest reduction in working hours. The quinary sector workers generally have more flexibility in their work and thereby have little impact on the working hours of women in this sector. 
Table 4: Results for Employment Status, by Industry

\begin{tabular}{|c|c|c|c|c|c|c|c|c|c|c|c|c|c|}
\hline COVID-19 & $\begin{array}{l}\frac{(1)}{-0.316^{20}} \\
(0.119)\end{array}$ & $\begin{array}{c}(2) \\
-1.503^{\text {मfन }} \\
(0.206)\end{array}$ & $\begin{array}{l}\text { (3) } \\
-1.184^{+12} \\
(0.0591)\end{array}$ & $\begin{array}{l}\frac{(4)}{-1.477^{712}} \\
(0.0655)\end{array}$ & $\begin{array}{c}(5) \\
-1.366^{612} \\
(0.0734)\end{array}$ & 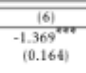 & $\begin{array}{c}77 \\
-1.544^{2727} \\
(0.0475)\end{array}$ & $\begin{array}{c}(8) \\
-0.734^{\text {(27 }} \\
(0.128)\end{array}$ & $\begin{array}{c}(9) \\
-1.268^{\text {fat }} \\
(0.0763)\end{array}$ & $\begin{array}{l}\frac{(10)}{-\left.3.09\right|^{+27}} \\
(0.181)\end{array}$ & $\begin{array}{c}(11) \\
-2.577^{\mathrm{Nem}} \\
(0.115)\end{array}$ & $\begin{array}{c}(12) \\
-1.137^{\mathrm{med}} \\
(0.0630)\end{array}$ & $\begin{array}{c}(13) \\
-0.579^{\text {per }} \\
(0.146)\end{array}$ \\
\hline Female & $\begin{array}{l}0.0472 \\
(0.173)\end{array}$ & $\begin{array}{c}-0.291 \\
\{0.389\}\end{array}$ & $\begin{array}{l}0.0905 \\
(0.163\}\end{array}$ & $\begin{array}{l}-0.140 \\
(0.100)\end{array}$ & $\begin{array}{l}-0.0160 \\
(0.122)\end{array}$ & $\begin{array}{l}-0.645^{44} \\
(0.215)\end{array}$ & $\begin{array}{l}-0.0524 \\
(0.0554)\end{array}$ & $\begin{array}{l}0.383^{* *} \\
(0.147)\end{array}$ & $\begin{array}{l}-0.248^{*} \\
(0.29966)\end{array}$ & $\begin{array}{l}-0.511^{* *} \\
(0.1899)\end{array}$ & $\begin{array}{l}0.08663 \\
(0.144)\end{array}$ & $\begin{array}{c}0.0888 \\
(0.0628)\end{array}$ & $\begin{array}{l}0.197 \\
\{0.173\}\end{array}$ \\
\hline COVID $19 \cdot$ Female & $\begin{array}{l}-0.290 \\
(0.235)\end{array}$ & $\begin{array}{l}1.170^{\circ} \\
\{0.548\}\end{array}$ & $\begin{array}{c}a .112 \\
(0.1966)\end{array}$ & $\begin{array}{l}0.0533 \\
(0.117)\end{array}$ & $\begin{array}{l}-0.169 \\
(0.141)\end{array}$ & $\begin{array}{c}0.460 \\
(0.263)\end{array}$ & $\begin{array}{c}-0.165^{*} \\
(0.0656)\end{array}$ & $\begin{array}{l}-0.549^{4 *} \\
(0.178)\end{array}$ & $\begin{array}{l}0.0714 \\
(0.116)\end{array}$ & $\begin{array}{l}0.612^{* * *} \\
(0.203)\end{array}$ & $\begin{array}{l}0.00314 \\
(0.164)\end{array}$ & $\begin{array}{l}-0.376^{* * *} \\
(0.0744)\end{array}$ & $\begin{array}{l}-0.412 \\
(0.210)\end{array}$ \\
\hline Children under 5 & $\begin{array}{l}-0.0286 \\
(0.170\rangle\end{array}$ & $\begin{array}{c}0.184 \\
\{0.250\}\end{array}$ & $\begin{array}{c}0.0434 \\
\langle 0.0883\}\end{array}$ & $\begin{array}{c}-0.122 \\
(0.0792)\end{array}$ & $\begin{array}{c}-0.3355^{* *} \\
(0.0926)\end{array}$ & $\begin{array}{c}0.338 \\
(0.228)\end{array}$ & $\begin{array}{l}-0.0812 \\
(0.0533)\end{array}$ & $\begin{array}{l}0.0579 \\
(0.151)\end{array}$ & $\begin{array}{c}0.0158 \\
|0.0930\rangle\end{array}$ & $\begin{array}{l}-0.229^{*} \\
(0.107)\end{array}$ & $\begin{array}{l}0.0551 \\
(0.137)\end{array}$ & $\begin{array}{c}0.0690 \\
\langle 0.0519\rangle\end{array}$ & $\begin{array}{l}-0.0956 \\
(0.183)\end{array}$ \\
\hline White & $\begin{array}{l}0.614^{2 * *} \\
(0.151)\end{array}$ & $\begin{array}{l}0.703^{* *} \\
\{0.218\}\end{array}$ & $\begin{array}{l}0.443^{20 *} \\
\langle 0.0763\}\end{array}$ & $\begin{array}{l}0.261^{4+4} \\
(0.0603)\end{array}$ & $\begin{array}{l}0.533^{4+4} \\
(0.0609)\end{array}$ & $\begin{array}{l}0.395 * \\
(0.147)\end{array}$ & $\begin{array}{l}0.39)^{+4+} \\
(0.0343)\end{array}$ & $\begin{array}{l}0.518^{4+4+} \\
(0.0990)\end{array}$ & $\begin{array}{l}0.23 \mathrm{~s}^{2+4} \\
(0.0633 \mathrm{y}\end{array}$ & $\begin{array}{l}0.560^{* 2 *} \\
(0.0683)\end{array}$ & $\begin{array}{l}0.566^{4+4} \\
(0.0840)\end{array}$ & $\begin{array}{l}0.155^{4+4} \\
(0.0356)\end{array}$ & $\begin{array}{c}0.461^{+40 *} \\
(0.107)\end{array}$ \\
\hline Age & $\begin{array}{l}0.0154^{\text {eat }} \\
(0.00351)\end{array}$ & $\begin{array}{c}0.0111 \\
(0.00706)\end{array}$ & $\begin{array}{l}-0.00119 \\
(0.00201)\end{array}$ & $\frac{0.00735^{4+4 *}}{(0.00195)}$ & $\begin{array}{c}-0.00962^{* * *} \\
(0.00226)\end{array}$ & $\begin{array}{r}0.00651 \\
(0.00487)\end{array}$ & $\frac{0.00819^{e+4}}{(0.00107)}$ & $\begin{array}{l}-0.00817^{44} \\
(0.00307)\end{array}$ & $\begin{array}{l}0.000+15 \\
(0.00210)\end{array}$ & $\begin{array}{l}0.00555^{*} \\
(0.00227)\end{array}$ & $\begin{array}{l}0.00945^{24 *} \\
\langle 0.00234\rangle\end{array}$ & $\begin{array}{l}0.00324^{4 *} \\
(0.00117)\end{array}$ & $\begin{array}{r}-0.00644 \\
(0.00472)\end{array}$ \\
\hline Married & $\frac{0.687^{* * *}}{(0.121)}$ & $\frac{0.629^{\cdots * *}}{\{0.183\}}$ & $\begin{array}{l}0.698^{* *} \\
(0.0571)\end{array}$ & $\begin{array}{l}0.465^{4 * *} \\
(0.0518)\end{array}$ & $\begin{array}{l}0.575^{4 * *} \\
(0.0600)\end{array}$ & $\begin{array}{l}0.550^{4 * * *} \\
(0.127)\end{array}$ & $\begin{array}{l}0.464^{4 * *} \\
(0.0373)\end{array}$ & $\begin{array}{l}0.361^{404+4} \\
(0.0894)\end{array}$ & $\begin{array}{l}0.671^{\cdots \cdots} \\
(0.0605)\end{array}$ & $\begin{array}{l}0.350^{6 *} \\
(0.0672)\end{array}$ & $\begin{array}{l}0.530^{4 * *} \\
(0.0801)\end{array}$ & $\begin{array}{l}0.383^{4 * *} \\
(0.0318)\end{array}$ & $\frac{0.643^{4 * *}}{(0.107)}$ \\
\hline College & $\begin{array}{c}0.698 \mathrm{~s}^{\cdots *} \\
(0.170)\end{array}$ & $\begin{array}{l}1.071 \cdots \cdots \\
\{0.272\}\end{array}$ & $\begin{array}{l}0.294 * * \\
(0.0810)\end{array}$ & $\begin{array}{l}0.887^{7 * *} \\
\langle 0.0647\rangle\end{array}$ & $\begin{array}{l}0.197^{* *} \\
(0.0668)\end{array}$ & $\begin{array}{l}0.782^{4+4 *} \\
(0.149)\end{array}$ & $\begin{array}{l}0.103^{* *} \\
(0.0398)\end{array}$ & $\begin{array}{l}0.399^{4 *+1} \\
(0.0868)\end{array}$ & $\begin{array}{l}0.690^{* \cdots} \\
(0.0607)\end{array}$ & $\begin{array}{c}0.181^{*} \\
(0.0823)\end{array}$ & $\begin{array}{l}0.564^{4 * *} \\
\langle 0.0768)\end{array}$ & $\begin{array}{l}0.675^{4 * *} \\
(0.0305)\end{array}$ & $\begin{array}{c}0.630^{* * *} \\
(0.105)\end{array}$ \\
\hline $\begin{array}{l}\text { Constant } \\
\text { Obsetvations }\end{array}$ & $\begin{array}{c}1.662^{* 2 *} \\
{[0.199\rangle}\end{array}$ & $\begin{array}{c}1.688^{2 * *+} \\
\{0.332\} \\
2185\end{array}$ & $\begin{array}{c}2.460^{200 *} \\
(0.119) \\
22350\end{array}$ & $\begin{array}{r}2685^{4 * 4} \\
(0.113) \\
31478\end{array}$ & $\begin{array}{c}3.237^{4+4} \\
(0.130) \\
21899\end{array}$ & $\begin{array}{c}2.787^{4+4 *} \\
(0.282) \\
6774 \\
\end{array}$ & $\begin{array}{c}\begin{array}{c}2.302^{+*+*} \\
(0.0601)\end{array} \\
51325\end{array}$ & $\begin{array}{r}3.424^{4+4} \\
(0.200)\end{array}$ & $\begin{array}{c}2.646^{* 4+*} \\
(0.116) \\
2317 t\end{array}$ & $\begin{array}{c}2.965^{* 2 *} \\
(0.196) \\
9504\end{array}$ & $\begin{array}{c}1.878^{444} \\
(0.136) \\
7211 \\
\end{array}$ & $\begin{array}{l}2.837^{+4 * *} \\
(0.0792) \\
91953\end{array}$ & $\begin{array}{r}3.359^{4+4 *} \\
(0.275) \\
16317\end{array}$ \\
\hline
\end{tabular}

Table 5: Results for Working Hours

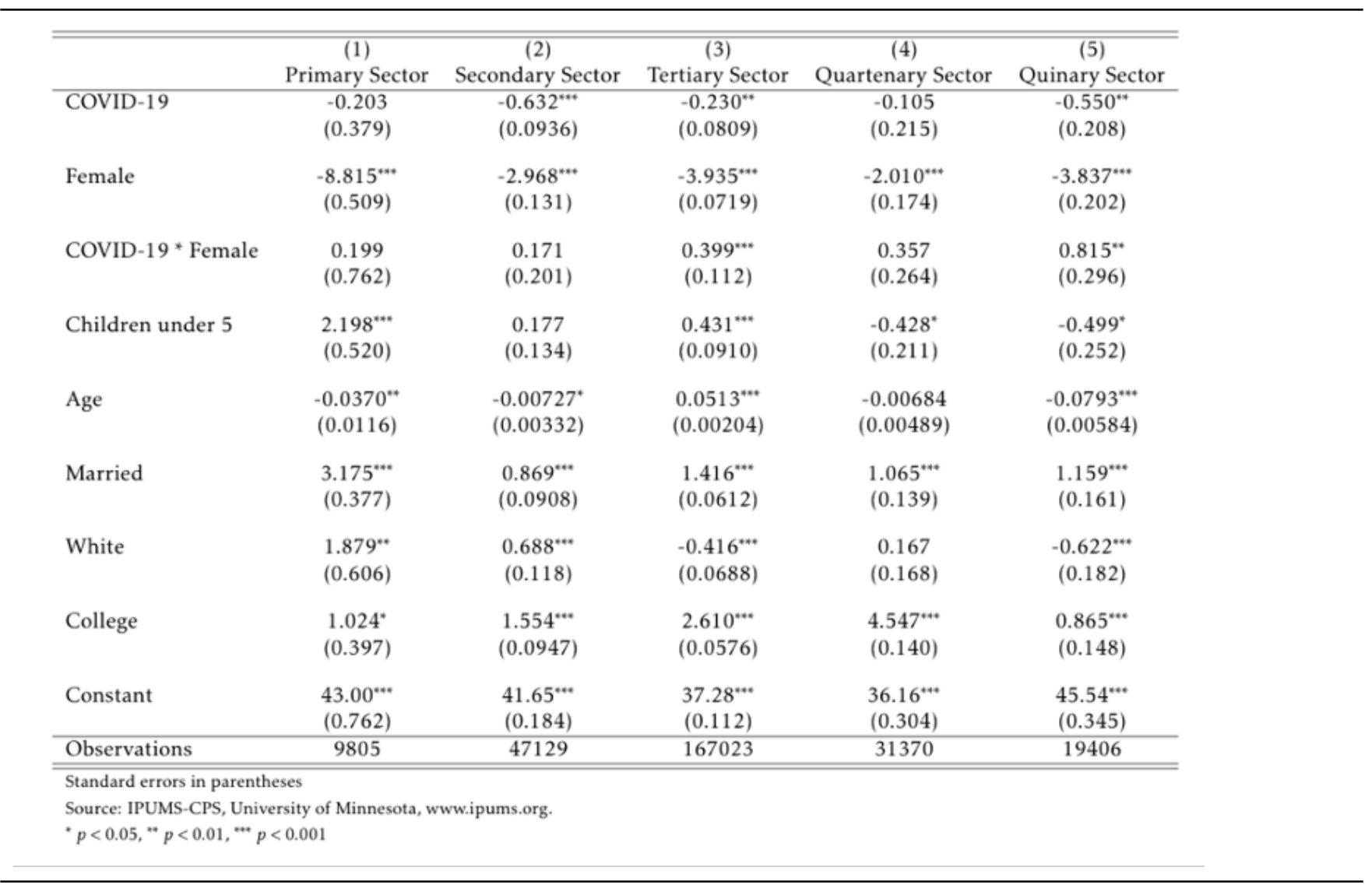


Table 6: Results for Working Hours, by Industry

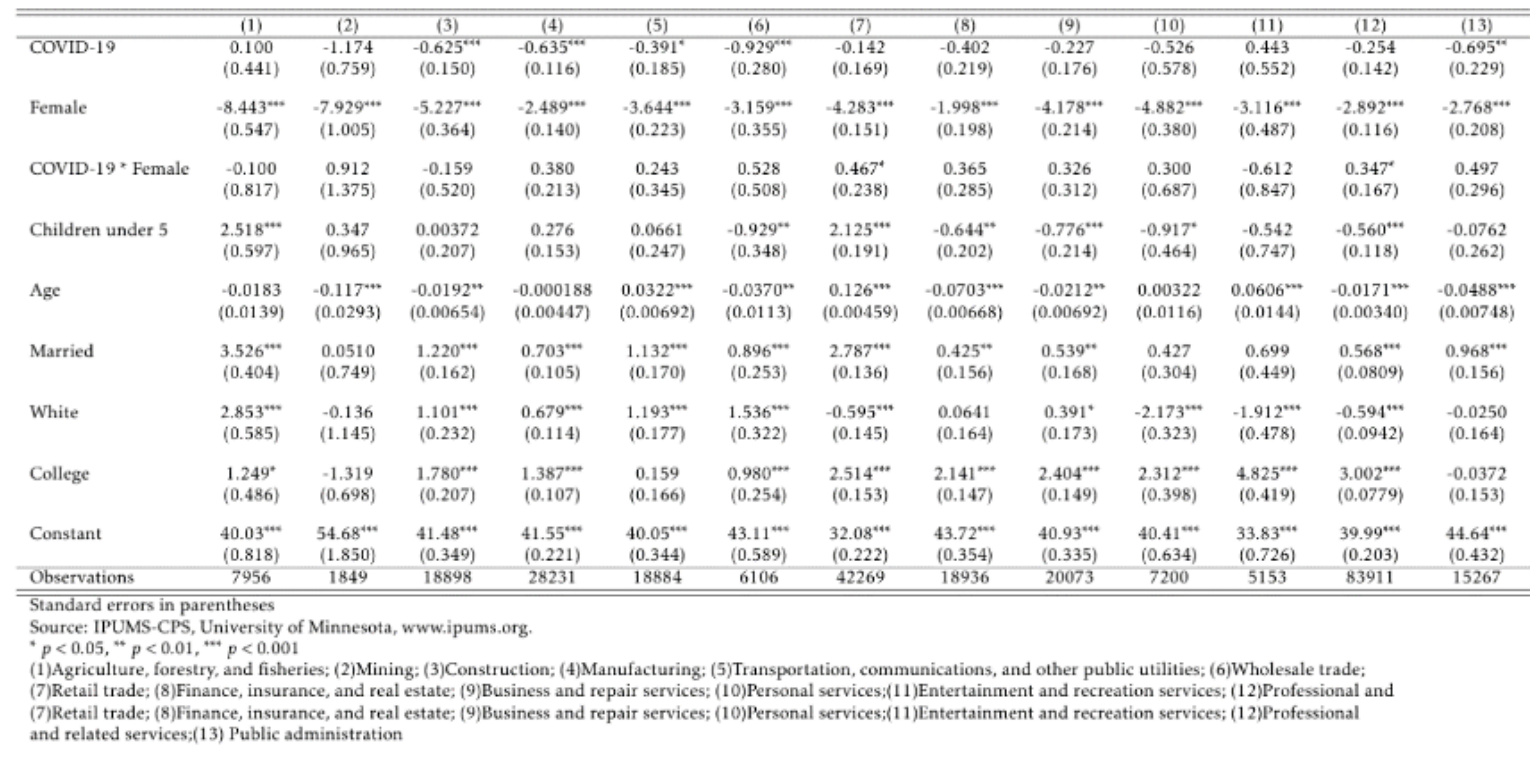

Similar to results in terms of employment status, marital status again plays a vital role in decreasing working hours for all sectors. According to Table 5, marriage increases working hours across all sectors. Married people are more likely to be employed, as discussed in the previous section, and tend to work for a longer time with the incentives to earn more income for the family. Having children under the age of five is shown to increase working hours for the primary and tertiary sector workers. However, it reduces hours for the quaternary and quinary sectors due possibly to more hours devoted to childcare [18].

Respondents who receive at least a college degree are more likely to have longer working hours, especially so in the quaternary sector where education-related industries occupy a huge part. Table 5 also reveals that white workers in the primary and secondary sector have more working hours than their non-white counterparts. This result is probably because the construction and manufacturing sectors usually pay hourly wages, an incentive for the workers to work for more hours. Contrarily, white workers in the tertiary and quinary sectors work for fewer hours.

\subsection{Working Remotely}

The results for working remotely are exhibited in Table 7. The primary, secondary, and tertiary sectors are less likely to work remotely after the pandemic, since most work in these three sectors is carried out in-person, rather than remotely. Conversely, the quaternary and quinary sectors have a slightly better ability than other sectors to transition to working remotely due to their preestablished reliance on communication technology. Over the course of the pandemic, many schools have been forced to work remotely and adjust their form of instruction, and the public administration as a large part of the quinary sector allows for telecommunication and presents the highest activity rate [15]. However, women in all sectors are more likely to work remotely due to COVID-19 than men working in the same sectors. This is because women usually perform jobs that require interpersonal elements, such as salespersons and waitresses.

In terms of household characteristics, marriage influences one's possibility to switch to the remote working mode. The results display that married people will have a higher likelihood of working remotely, since they usually have stable housing and accessibility to teleworking technologies compared to unmarried people. Having children under five does not significantly affect the probability of working remotely.

Working from home also reveals disparities based on age, race, and educational attainment, as the ability to telecommute is not a privilege enjoyed by workers from all backgrounds. Older people are less willing to work remotely generally because they are less accepting and adaptive to the internet and technology. More educated workers tend to work remotely, as most higher-educated workers are in knowledge sectors that allow them to telework or even equip them with necessary devices. White workers are more averse to working remotely.

\section{ROBUSTNESS CHECK}

In this section, I provide results from several tests: a placebo test on the effect of COVID-19, a time-sensitivity test on time-span selected for regression, and a robust regression excluding possible outliers and heteroskedasticity.

I check the assumption that the impacts are caused by COVID19 instead of time lapses through a placebo test. I set January of 
Table 7: Results for Working Remotely

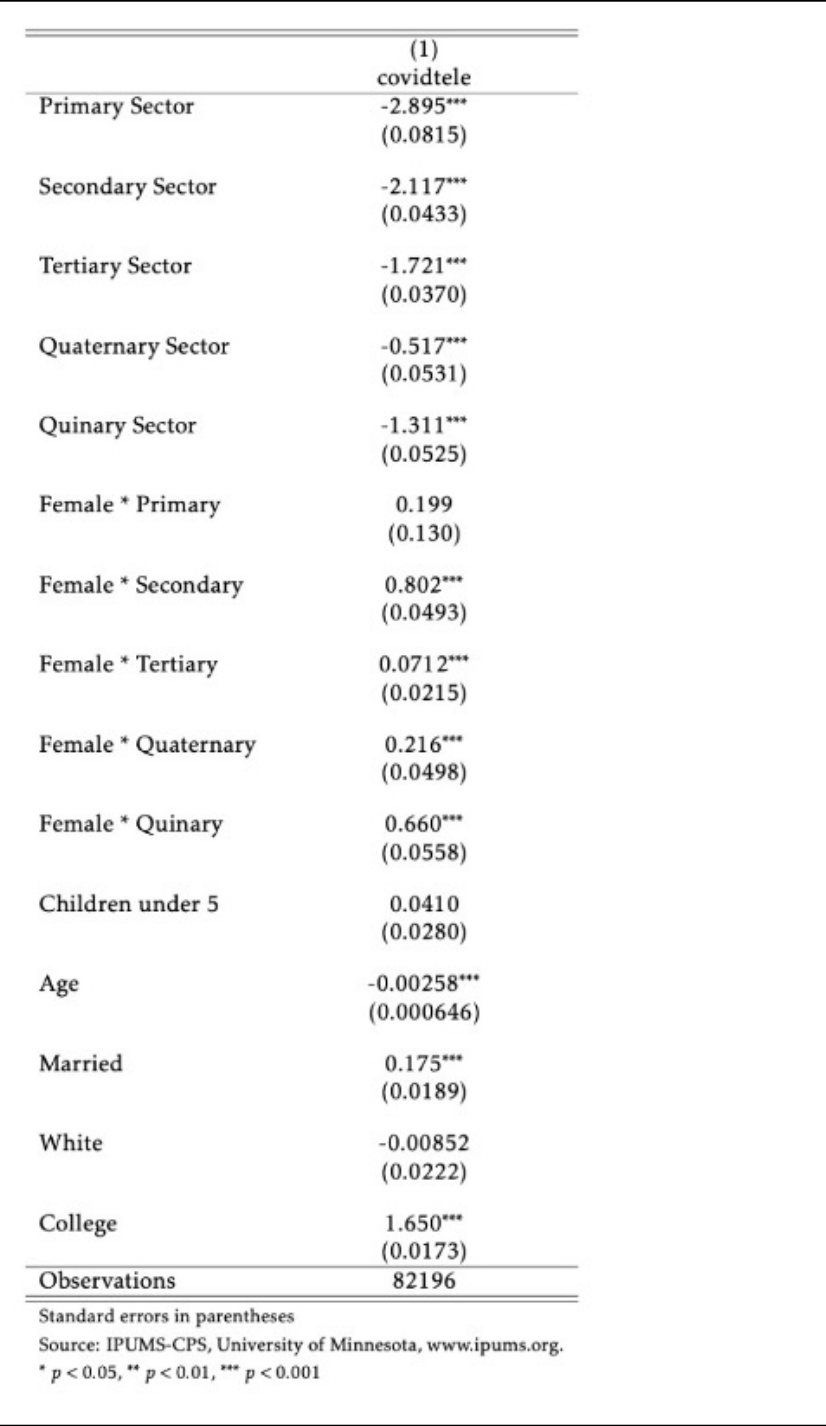

2019 and 2020 as the control group for comparing with the second quarter of 2019 and 2020. The purpose is to test if a "pseudo treatment"' will have any effect on the regression results. Based on the robustness check results, the coefficients for the COVID-19 and COVID-19 Female variables are not significant and lower than those in the original regression. This corroborates the belief that the employment status and working hours of the respondents in January have not yet been impacted by COVID- 19 .

Another assumption is that only COVID-19, instead of any other disruptive events, made significant impacts on the economy during the second quarter of 2019-2020. I test the time sensitivity of the models by comparing results in May 2019 and in May 2020, replacing one quarter with only one month. The final results confirm that the robustness of models in terms of time selection.

Lastly, my analysis assumes that the OLS model concerning working hours does not have any heteroskedastic errors. To address this assumption, I test the presence of heteroskedasticity. It turns out that the results are still robust, and that the heteroskedastic errors are negligible in this case. Although there are many other robustness checks, they are rather unnecessary in this situation.

\section{CONCLUSION}

In this paper, I empirically investigate the impacts of COVID-19 on gender inequality in labor markets and underscore the variation in effects across sectors. Based on the results and analysis, I reach the following conclusions: The COVID-19 pandemic influences all sectors to different degrees, with the tertiary (service) sector hit the hardest. The pandemic has also posed exacerbating challenges to gender inequality in certain sectors, but not all. Women working in the tertiary are most harmed, while sectors that rely mostly on knowledge and technology tend to work remotely and generally have the least impact in working hours by the pandemic. Analysis of employment status captures the more general economic repercussions from the pandemic, while investigation into the working hours reflects more about gender inequality. The intersectionality of race, gender, and educational attainment contributes to the disparities in labor markets across all sectors. Marriage benefits employment across all sectors, yet having children under the age of five could slightly disadvantage workers in certain sectors.

However, this paper has several limitations. Data is limited because of the short time period, and the long-term effects of COVID19 on gender inequalities still remain unclear. Future studies could more closely examine the interactions of gender, race, education, and marital status in impacting employment in the labor markets.

\section{REFERENCES}

[1] R Maria del Rio-Chanona, Penny Mealy, Anton Pichler, François Lafond, and J Doyne Farmer. 2020. Supply and demand shocks in the COVID-19 pandemic: an industry and occupation perspective. Oxford Review of Economics, Vol. 36. DOI: https://doi.org/10.1093/oxrep/graa033

[2] Scott R Baker, Robert A Farrokhnia, Steffen Meyer, Michaela Pagel, and Constantine Yannelis. 2020. How Does Household Spending Respond to an Epidemic? Consumption during the 2020 COVID-19 Pandemic. Review of Asset Pricing Studies. https://doi.org/10.1093/rapstu/raaa009

[3] Martin S. Eichenbaum, Sergio Rebelo, Mathias Trabandt. 2020a. The macroeconomics of testing and quarantining. No. w27104. National Bureau of Economic Research.

[4] Seungho Baek, Sunil K. Mohanty, and Mina Glambosky. COVID-19 and stock market volatility: An industry level analysis. Finance Research Letters 37 (2020): 101748.

[5] Claudiu Tiberiu Albulescu. COVID-19 and the United States financial markets' volatility. Finance Research Letters 38 (2021): 101699.

[6] Louis-Philippe Béland, Abel Brodeur, and Taylor Wright. The short-term economic consequences of Covid-19: exposure to disease, remote work and government response. 2020.

[7] Abi Adams-Prassl, Teodora Boneva, Marta Golin, and Christopher Rauh. Inequality in the impact of the coronavirus shock: Evidence from real time surveys. Journal of Public Economics 189 (2020): 104245.

[8] Marta Fana, Sergio Torrejón Pérez, and Enrique Fernández-Macías. Employment impact of Covid-19 crisis: from short term effects to long terms prospects. Journal of Industrial and Business Economics 47, no. 3 (2020): 391-410.

[9] C. T. Vidya, and K. P. Prabheesh. Implications of COVID-19 pandemic on the global trade networks. Emerging Markets Finance and Trade 56, no. 10 (2020): 2408-2421.

[10] Liana Christin Landivar, Leah Ruppanner, William J. Scarborough, and Caitlyn Collins. Early Signs Indicate That COVID-19 Is Exacerbating Gender Inequality in the Labor Force. Socius 6 (2020): 2378023120947997.

[11] Tali Kristal, and Meir Yaish. Does the coronavirus pandemic level the gender inequality curve?(It doesn't). Research in Social Stratification and Mobility 68 (2020): 100520.

[12] Phyllis Moen, Joseph H. Pedtke, and Sarah Flood. Disparate disruptions: Intersectional COVID-19 employment effects by age, gender, education, and 
race/ethnicity. Work, aging and retirement 6 , no. 4 (2020): 207-228.

[13] Paula England. Gender inequality in labor markets: The role of motherhood and segregation. Social Politics: International Studies in Gender, State \& Society 12 no. 2 (2005): 264-288.

[14] Titan M. Alon, Matthias Doepke, Jane Olmstead-Rumsey, and Michele Tertilt. The impact of COVID-19 on gender equality. Working Paper. National Bureau of economic research, 2020a.

[15] Lídia Farré, Yarine Fawaz, Libertad González, and Jennifer Graves. How the COVID-19 lockdown affected gender inequality in paid and unpaid work in Spain. (2020).

[16] Konstantinos Pouliakas, and Jiri Branka. EU Jobs at Highest Risk of COVID-19 Social Distancing: Will the Pandemic Exacerbate Labour Market Divide? (2020).

[17] X. Cao, D. Zhang, and L. Huang. The Impact of COVID-19 Pandemic on Gig Economy Labor Supply. (2020).

[18] Caitlyn Collins, Liana Christin Landivar, Leah Ruppanner, and William J. Scarborough. COVID-19 and the gender gap in work hours. Gender, Work \& Organization 28 (2021): 101-112.

[19] Gema Zamarro, Francisco Perez-Arce, and Maria Jose Prados. Gender Differences in the Impact of COVID-19. Working Paper. Switzerland: Frontiers in Public
Health. Retrieved from https://tinyurl. com/CESRGenderDiffs, 2020

[20] Yue Qian, and Sylvia Fuller. COVID-19 and the gender employment gap among parents of young Children. Canadian Public Policy 46, no. S2 (2020): S89-S101.

[21] Malte Reichelt, Kinga Makovi, and Anahit Sargsyan. The impact of COVID-19 on gender inequality in the labor market and gender-role attitudes. European Societies (2021),23: sup1, S228-S245, DOI: 10.1080/14616696.2020.1823010

[22] David Richardson, and Richard Denniss. Gender experiences during the COVID19 lockdown. The Australia Institute (2020).

[23] Titan Alon, Matthias Doepke, Jane Olmstead-Rumsey, and Michèle Tertilt. This time it's different: the role of women's employment in a pandemic recession. No. w27660. National Bureau of Economic Research, 2020.

[24] Arthur Huang, Christos Makridis, Mark Baker, Marcos Medeiros, and Zhishan Guo. Understanding the impact of COVID-19 intervention policies on the hospitality labor market. International Journal of Hospitality Management 91 (2020): 102660.

[25] John Bluedorn, Francesca Caselli, Niels-Jakob Hansen, Ippei Shibata, and Marina M. Tavares. Gender and Employment in the COVID-19 Recession: Evidence on "She-cessions". No. 2021/095. International Monetary Fund, 2021. 